\title{
On the Part of Ratified Participants: RATIFIED Listeners In Multi-PARTy InTERACTIONS
}

\begin{abstract}
This paper aims to elucidate the categories of listening ratified participants in multi-party interactions in the light of the existing literature on participation frameworks. First of all, a distinction is drawn between an addressed ratified participant, the addressee, and an unaddressed ratified participant, dubbed the third party, whose subtypes are teased out. A crucial modification in the proposed classification of participants concerns an individual, commonly regarded as the bystander/overhearer, who is ratified and attains the status of the third party, thanks to the speaker's intention to communicate meanings to him/her. Several subordinate phenomena are also highlighted, such as the change of roles halfway through a turn, or collective roles. The discussion of participatory phenomena is illustrated with verisimilar examples taken from a popular American series entitled "House".
\end{abstract}

\section{Key words}

Addressee; Goffman; hearer/listener types; multi-party interaction; ratified participants; third party; turn-taking

\section{Introduction}

Human interactions cannot be reduced merely to exchanges of two participants, given the multiplicity of hearers in everyday communication and media discourse. Several authors have observed the need to distinguish a range of diversified participatory roles, extending the classic dyadic model of communication, which involves the speaker and the hearer/listener, and putting forward independent, albeit to an extent comparable, participation frameworks (Hymes 1972, 1974; 
Goffman 1981a [1976], 1981c [1979], 1981d; Bell 1984, 1991; Thomas 1986; Levinson 1988; Clark and Carlson 1982; Schober and Clark 1989; Clark and Schaefer 1987, 1992; Clark 1996; Verschueren 1999). A new version of a participatory model has been championed, based on a review of these proposals and a clarification of a number of conceptual and terminological problems underlying participation (see Dynel 2010a, 2010b, 2010c, 2011c, 2012).

On the whole, a participant is an individual who takes part in a given turn (not necessarily the whole interaction), either as the speaker or as the hearer/ listener. The two terms are here used synonymously, regardless of the difference between the ordinary meanings of the verbs "hear" and "listen", in reference to an individual who can hear, and does listen to, a turn and has the capacity to understand it. Participants bifurcate into the ratified and unratified types. The latter comprise only unratified hearers/listeners, i.e. overhearers, to whom the speaker does not wish to communicate any meanings and who are divided into bystanders and eavesdroppers. The speaker, and usually (but not always) ratified hearers, are cognisant of a bystander's presence and capacity to listen, whereas they are oblivious to an eavesdropper, who may be sometimes engaged in a stealthy activity. On the other hand, ratified participants, also called interlocutors or conversationalists, comprise the speaker, a participant whose turn is in progress (Goodwin 1981), and ratified hearers/listeners. A ratified hearer/listener is an individual who can hear and does listen according to the speaker's intention.

The present article concerns ratified hearers and is inspired by Goffman's observation that "The relation(s) among speaker, addressed recipient ${ }^{1}$, and unaddressed recipient(s) are complicated, significant and not much explored" (1981c [1979]: 133). Despite the lapse of time and the research that has been done, this remark does not appear to have lost its relevance. The aim here is to elaborate on the roles at the reception end, as projected by the speaker. Some new light will then be shed on ratified hearers/listeners, who are divided into: the addressee, and an unaddressed ratified hearer, i.e. the third party (Dynel 2010b). Different authors offer different terms to capture the latter category: the hearer/receiver/audience (Hymes 1972, 1974); the unaddressed hearer/listener (Goffman 1976 1981a [1976], 1981c [1979], 1981d); the auditor (Bell 1984, 1991), the indirect target or the audience ${ }^{2}$ (Levinson 1988), and the side participant (Clark and Carlson 1982; Schober and Clark 1989; Clark and Schaefer 1987, 1992; Verschueren 1999). In essence, the addressee is a hearer to whom the speaker overtly and primarily directs a given utterance by dint of address cues, whilst the third party is a ratified listener to whom an utterance is not addressed but is, nonetheless, directed. Therefore, the third party is also fully entitled to listen to it and make inferences, according to the speaker's communicative intention. The primary objective here is to investigate participatory phenomena pertinent to the ratified hearers. Attention is paid to the subtypes of third parties, depending on their statuses in interactions.

The typology of ratified hearers endorsed here assumes a turn as the basic analytic unit. It is defined as a stream of speech of varied length terminated by 
a pause and/or another interactant's verbal or non-verbal contribution. However, sometimes a turn may be realised as a non-verbal signal, such as a facial expression or a gesture, or as a written utterance (e.g. in computer-mediated conversation), which has no bearing on the technical terms denoting participants. The producer of a non-verbal or written turn is the speaker, and its receiver is called the hearer. A turn usually coincides with an utterance, but it may also comprise a few utterances directed to distinct hearers. Participants keep changing roles as their conversation develops, according to turn-taking procedures (e.g. Schegloff and Sacks 1973, Sacks et al. 1974), while one role may be simultaneously performed by a number of individuals, in which case it earns the epithet collective.

The examples in this paper are grouped in reference to the central phenomena addressed but are discussed in detail in the context of various participatory issues. The discourse of a television series is chosen as the source of exemplification data, inasmuch as it inherently entails the role of an outside observer, i.e. the viewer, dubbed the recipient (Dynel 2010a, 2011a, 2011b), but is in many ways reminiscent of everyday talk (cf. Dynel $2011 \mathrm{~b}$ and references therein). Conversing characters bear resemblance to conversationalists in real-life interactions, the most significant difference being that the former's interactions are, by nature, available to an outside hearer, i.e. the film viewer. This is the underlying goal of the film production crew, who design film discourse for the audience's (recipients') benefit. Support then is here given to Coupland's (2004: 258) premise: "My motive in using fictional, media texts is partly based in the belief (cf. Grimshaw 1996) that fictionalised reality can sometimes reveal social processes more clearly than lived reality." Indeed, film discourse lends itself perfectly to linguistic analysis, even when no attention is paid to the peculiarities of film discourse as such, which is the case here. The nature of interactions and participant roles performed by characters tends to be clearer than in the case of natural discourse. Consequently, based on all information provided on the screen, the viewer-researcher (the metarecipient, cf. Dynel 2011a, 2011b) can recognise various participatory phenomena, as well as conjecture fictional speakers' intentions.

The exemplification data have been culled from a widely acclaimed medical drama series entitled "House". Based in the USA, it has gained worldwide popularity thanks to the eponymous character, a perspicacious diagnostician who engages in scintillating conversations with his patients and the other doctors. In each episode, Dr House and his changing team members (conventionally referred to by their surnames only) are absorbed in a peculiar medical case. Scenes in which the doctors are trying to solve the central conundrum are intertwined with those showing changes in their personal lives, as well as minor cases of clinic patients. Each extract of an interaction is preceded by a description of contextual factors, and the most significant non-verbal signals are presented if they are of central importance to the communicated meanings. 


\section{The addressee vs. the third party}

The addressee is a hearer/listener role easily determined in dyadic interactions, when only one ratified individual is listening to the speaker. In multi-party interactions, however, a number of problems arise in the context of differentiation between the addressee and the third party. It is sometimes assumed that the addressee is a participant entitled to answer (Goffman 1981c [1979]: 133). However, this claim is not entirely tenable, since sometimes no reply at all may be expected from the addressee in some contexts (e.g. Dr House lecturing a student). Moreover, this criterion will also be fallible if the addressee is collective, i.e. performed by a number of individuals, each of whom would not be able to be listened to if responding simultaneously (e.g. Dr House asking his team for a diagnosis). On the whole, as many examples below will bear out, whether a third party or an addressee, a ratified hearer is frequently entitled to react verbally (or non-verbally), unless constrained by regulations typical of certain formal situations, for instance in a court of law or during official ceremonies. Also, directing his/her turn to a number of ratified hearers, the speaker need not envisage from whom the response will come. Sometimes the speaker's turn may even be inherently predicated on the equipotentiality principle (cf. Clark and Carlson 1982), inviting a contribution on the part of any hearer who finds himself/herself obliged or invited to reply or simply wants to do so. Furthermore, having performed the role of a listener, a speaker may legitimately self-select to take the floor (Sacks et al. 1974: 711), irrespective of whether he/she has just been addressed or even talked to (hitherto having been an unratified participant). It is evident that the right to respond is by no means a foolproof indicator of the dichotomy between the addressee and the third party, which is why another criterion must be sought.

Goodwin (1981) states that in the case of multi-party turns, utterances are constructed together with displays of incumbency, whereby address/non-address (and hearership/nonhearership, in general) are signalled. Participants jointly negotiate their statuses via non-verbal means (e.g. eye gaze ${ }^{3}$ ) and verbal means (e.g. second person pronouns) (Goodwin 1979, 1981). Also, all cues are subject to "momentby-moment permutation and transposition" (Sidnell 2009: 151). This means that the division of hearers into the addressee and the third party is dependent on constant turn-taking procedures and can change even halfway through the speaker's turn, as many examples quoted here will indicate. The importance of non-verbal cues is manifest in the following example.

(1) [House and the male team members (Doctors Chase, Taub and Foreman) are gathered in the hallway outside the patient's room and are discussing a difficult case they have not been able to solve. They have no woman on the team, with Remy "Thirteen" Hadley having left.]

1. Taub: We're dead on our feet. I've barely slept in four days.

2. House: [looking at Taub] Aw... that's sad. You know what's even sadder? Thirteen was the only man on my team. 
3. Foreman: Yeah, it'd be nice if you hurry up and hire someone to fill her spot.

4. House: [looking at Foreman] Do it. Cuddy wants it to be a girl.

5. Foreman: There are a couple of people-

6. House: I was talking to Chase. I was just looking at you to screw with you.

Episode 3, Season 7, "Unwritten"

Taub produces an utterance on behalf of himself and the other two members of the team (1), thereby provoking the addressee's reply (2). Admittedly, House addresses the turn to the previous speaker but simultaneously treats the remaining two interlocutors practically on an equal basis (cf. the first type of the third party discussed in Section 3.1), i.e. as the collective third party constituted by Chase and Foreman, to whom the utterance is of equal relevance. Foreman, earlier a member of the third party, then takes the floor and addresses House (3). As a result, to take revenge on Foreman for issuing the request, House appears to address him by deploying the unequivocal non-verbal cue (4), while actually meaning to verbally address Chase, to which he later admits (6), having elicited Foreman's response (5).

On the other hand, non-verbal cues may be reduced to a minimum. For instance, the speaker may simply produce a turn without transparently choosing one hearer as the addressee, failing even to look at him/her (Sidnell 2009), for instance because of his/her shyness, the arrangement of chairs, or an auditory channel (e.g. a telephone conversation with the use of a speakerphone) that disallows $\mathrm{him} / \mathrm{her}$ to do so. Additionally, the speaker may be unable to maintain eye contact with all members of the collective addressee simultaneously, while his/her utterance may be devoid of pronouns or names indicative of address. Frequently, it is then the import of an utterance and/or its relation to the preceding turn that helps determine who the (collective) addressee is. By way of illustration, most brainstorming-based diagnostic discussions House holds with his team are based on consecutive speakers' turns addressed to everybody present, sometimes interspersed with turns or utterances within, addressed only to chosen individuals.

(2) [The team, Doctors Robert Chase, Eric Foreman and Allison Cameron, are in front of the whiteboard in the conference room when House rushes in.]

1. House: [not looking at anybody present] Who electrocuted my patient?

2. Foreman: He had a seizure.

3. Cameron: He wasn't electrocuted.

4. House: [turned back to everybody, searching through some books on his shelves] What does the seizure tell us? [He turns around to see Chase leaning against the desk] Move.

5. Cameron: What are you looking for?

6. House: Same as you. Love, acceptance, solid return on investment. [looking down, searching through the papers on the desk] Differential diagnosis, go. 
7. Chase: Could be epilepsy or seizure disorder.

8. Cameron: Not with the tachycardia. It could be a virus in his brain.

9. Chase: Specificity is impressive. Adrenolukodystrophy.

10. Foreman: Could be MS, seizures could be caused by plaques and lesions on the brain.

11. House: [He finally finds the file he has been looking for on another table and picks it up.] Well let's find out which. Get an MRI. [He walks out.]

Episode 12, Season 2, "Distractions"

In the example above, House's turn (1) opens with a question contingent on the equipotentiality principle, inviting a response on the part of any hearer from among the collective addressee, i.e. Chase, Foreman and Cameron. As a result, two replies are provided consecutively ( 2 and 3 ), both subverting the presuppositions underlying House's question. Although not supported by non-verbal cues, as he is not looking at the interlocutors, House's next turn (4) also entails a question addressed to all the hearers, which is signalled by the second person plural pronoun "us" indicative also of self-reference. This is followed by an order addressed to only one hearer, Chase, who is visually selected. A similar structure of a turn entailing a change in address manifests itself in turn (6), as evident from its content. The speaker first addresses the author of the preceding turn, with the other hearers performing the role of the collective third party, and then he produces a request towards the collective addressee. In their tentative diagnoses, Chase (7) and Foreman (10) address all the parties present, while Cameron's (8) and Chase's (9) contributions open with chunks of text addressed to the preceding speakers (Chase and Cameron, respectively) but directed to the collective third party only to close with utterances conveying their diagnoses addressed to everybody present. Finally, House's closing turn (11) entails not only a collective address but also self-address.

In the light of the above, the distinction between the addressee and another ratified participant, called the third party, can be made on the strength of the relevance of meaning to the hearers (which may involve responding to their previous turns), together with (non-)verbal cues. Nonetheless, this distinction may sometimes be difficult to make given equivocal non-verbal cues. Actually, this distinction happens to be of little importance, as long as the speaker means both types of ratified hearers, each performed by single or many individuals, to listen to his/her utterance and interpret it. All the same, several subtypes of the third parties can be identified.

\section{Types of the third parties}

Whilst a few researchers have drawn a distinction between the addressee and an unaddressed ratified hearer, no attempt appears to have been made so far at subdividing the latter, excepting Levinson's (1988) dichotomy between the "indirect 
target" and the "audience". Here, the categories of third parties are distinguished in accordance with the nature of the speaker's turn, based on the meaning's relevance to the third party, which determines the exact participatory position of the third party in the interaction as a given turn is performed. The five categories listed below appear to be the most salient ones.

\subsection{The third party with rights equal to the addressee's}

The third party frequently participates in a turn on a similar basis as the addressee, even if appreciating that it is technically addressed to another individual, for example by answering his/her preceding question. Therefore, the speaker's overt choice of the addressee has no bearing on the speaker's communication of meanings to both types of ratified hearers, who are equally important from the speaker's vantage point. However, meanings communicated to, and inferred by, each hearer may sometimes be significantly different (Clark and Carlson 1982, Dynel 2010c), which applies to all addressee and third party configurations discerned here.

(3) [House enters a female patient's (Alex's) room. Her father is present.]

1. House: We found a tumor.

2. Dad: She has cancer...

3. House: Technically, no.

4. Dad: So it's not cancer?

5. House: No, it's cancer. But, HE has cancer, on his left testicle.

6. Alex: I don't have testicles.

7. Dad: She's not a guy.

8. House: His DNA says you're wrong. Frogs and snails and puppy dog tails. You've got male pseudohermaphroditism. See we all start out as girls and then we're differentiated based on our genes. The ovaries develop into testes and drop. But in about 1 in 150,000 pregnancies a fetus with an XY chromosome, a boy develops into something else. Like you. Your testes never descended because you're immune to testosterone. You're pure estrogen, which is why you get heightened female characteristics; clear skin, great breasts. The ultimate woman is a man. Nature's cruel, huh?

9. Dad: This is obviously a joke, this is impossible.

10. House: No, a joke would be me calling you a homo. See the difference? I'll schedule him for surgery.

11. Alex: [She gets out of bed] No, you're wrong. I'm a girl. [She pulls off her gown] Look at me! How could you say I'm not a girl? See! They're all looking at me. I'm beautiful!

12. House: Anger, it's just the cancer talking. Put your clothes back on. I'm going to cut your balls off. Then you'll be fine.

13. [Alex covers up, crying]

Episode 13, Season 2, "Skin Deep" 
With no cues indicating otherwise, House seems to address his first turn (1) to both the ratified hearers, which prompts one of them to address him in response (2). In his immediate reply (3), House appears to address this interlocutor, with the other one performing the role of the third party, to whom this utterance is of equal importance, inasmuch as it concerns her health. However, it is again the addressee that takes the floor as the next speaker, selecting House as the addressee (4). In the reply addressed to the father (5), the speaker refers to the unaddressed ratified hearer (the third party) in the third person singular. This peculiar pronoun change motivated by the doctor's medical discovery pertaining to the third party underlies also two other turns $(8,10)$. This does not mean, however, that Alex has interactional rights different from the ones enjoyed by the addressee (the father). The girl even self-selects as the speaker (6). Additionally, in other turns $(8,10$, and 12), House changes the address halfway through, addressing alternately the patient or her father, or addressing the two hearers simultaneously while impersonally explaining the medical condition. Interestingly, the alternate address shows in the use of pronouns "you" and "him" in reference to the same individual, namely Alex in turn (10). Perhaps with the exception of his direct request submitted towards the patient (12), House treats both hearers equally and relays messages to them, notwithstanding the overt address.

\subsection{The third party as the primary listener next to the dummy addressee}

The role of a dummy addressee comes into play when the speaker addresses an utterance to an individual who cannot grasp the emerging meaning, which is thus communicated only to the third party, the primary hearer. The speaker is well aware that the addressee will stand little chance of comprehending a turn, due to the insurmountable linguistic or cognitive obstacles the latter experiences, such as being a foreigner with no competence in a given language (cf. Example 4), a young child without the capacity to make complex inferences, or a non-human entity. Also, the dummy addressee may be a non-participant, an individual absent from the place of an interaction or even a non-existent individual. In such situations, the dummy addressee is unable to hear a turn, to the effect that, in dyadic interactions, the third party is the sole hearer. Generally, the dummy addressee is not the receiver (cf. Levinson 1988) of a message, regardless of whether he/she can hear it or listens to it.

(4) [In the clinic room, House has been diagnosing a Mandarin woman who does not speak English and is accompanied by her daughter. House diagnoses the patient with a cold, but the girl insists that her mother has hormonal problems and demands that she be prescribed contraceptive pills. House instantly discovers that it is the girl that will use them.]

1. House: What exactly was your plan? [He clicks his pen and begins writing a prescription.] You were going to exchange the birth control 
pills for some over the counter decongestants in the hopes that your mom's cold lasts for another six years?

2. Daughter: No.

[House pulls off the prescription paper and hands it over.]

3. Daughter: That for a cold?

4. House: No. That's for your ovaries. I assume you haven't had a stroke, have you ever had a blood clot?

5. Daughter: No.

6. House: Super. In three months when you need a refill, take a bus to a free clinic. Don't wait around hoping for mom to get another sniffle. [stands upright once more, then leans closer to the Mandarin mother] Not the sharpest chopstick in the drawer, is she?

7. Mandarin Woman: [She seems to happily thank him in Mandarin] Episode 18, Season 2, "Sleeping Dogs Lie"

Throughout their interaction, House and the teenage girl (1-6) do not wish to communicate any meanings to the Mandarin woman, except for the final part of House's last utterance (6). The two turn-taking conversationalists display indifference (Clark and Schaefer 1992) to her, paying no heed to whether or not she can grasp any meanings. Moreover, it may even be argued that, from the girl's perspective, indifference merges with concealment (Clark and Schaefer 1992), insofar as she does not want her mother to understand the conversation and capitalises on the fact that she must resort to English, unavailable to her mother as it is. Although legitimately within earshot, the woman is incapable of inferring any meanings and seems to be more of a present non-participant in the course of this verbal interaction performed by the two interlocutors, who alternately take the roles of the speaker and the addressee. However, at the end of his last turn (6), House overtly addresses the mother, who cannot be privy to the meaning conveyed, of which he is cognisant. She is then only a dummy addressee, whilst the only listener to the utterance is the third party, whom the speaker wishes to disparage and put ill at ease, only pretending to be talking to the mother. However, the alleged addressee does make a default, albeit spurious, inference about the meaning the speaker has communicated to her (i.e. that she will be fine soon) and thanks him profusely (7).

\subsection{The third party as a spectator or a referee}

In various interactional situations, the third party may play the role of a spectator or a referee/judge, listening to a turn or, frequently, verbal exchange performed by a dyad (or more interlocutors). Engaging in a communicative exchange anchored in turn-taking, two conversationalists (or more) do harbour intentions to be listened to with a view to being evaluated by the third party. The latter does not contribute verbally to (this part of) the interaction but does participate by listening. The ultimate evaluation corresponds to the speakers' particular objectives 
concerning the third party, i.e. entertainment with witty repartee, or validating the correctness of their opinions or suggestions, to name but a few.

(5) [House and Allison Cameron are meeting Lisa Cuddy, Dean of Medicine, to adjudicate on House's provocative proposal that they search their patient's wife.]

1. House: She agreed to let me search everywhere else, but this she says no to. Doesn't that tell you something?

2. Cuddy: Yes, that she doesn't want some lunatic doctor searching her vagina with a flashlight.

3. House: Cameron can do that.

4. Cameron: I am not going to -

5. House: The woman hasn't left the hospital since they arrived. Whatever she's using she's obviously hiding somewhere.

6. Cameron: She's not poisoning him!

7. House: It's the only explanation!

8. Cameron: No, it's the only explanation your twisted mind can come up with because you're angry that you can't find the answer and you're taking it out on her!

9. House: And you are protecting a complete stranger based on some childishly romantic notion that people are all so happily married they don't want to kill each other!

10. Cameron: Are you calling me childish?

11. House: Grow up.

12. Cuddy: Shut up. Both of you. And stay away from his wife. Sorry, I'm not giving you permission to assault someone.

Episode 15, Season 2, "Clueless"

This interaction opens with House's turn addressed to Cuddy (1) and her relevant reaction (2). Listening to both of these turns, Cameron enjoys the status of the third party. This is also the case in turn (3), whose content is of immediate relevance to her. The request House indirectly issues towards Cameron causes her to produce a response (4), which develops into an interchange between the two interlocutors, who take alternate turns in the role of the speaker and the addressee (5-11). They interact without inhibitions as if they were alone, yet nurturing an assumption that they are being listened to by the third party, i.e. Cuddy, who will decide on the course of action to be taken. She takes the position of a distanced judge witnessing the acrimonious exchange, enjoying the power of imposition and the right to take the floor, which she finally does (12).

\subsection{The third party seemingly neglected}

The third party may be treated as if he/she were a bystander or even a non-participant, to whom the speaker displays marked indifference, while tacitly ac- 
knowledging his/her ratified hearership. Therefore, the speaker's turn appears to violate the neglected third party's communicative rights or otherwise flies in the face of conversational etiquette, for instance due to its hurtful content or lack of relevance to the third party. This type of ratified hearership seems to be much less frequent than the other ones.

(6) [Sebastian, a doctor who treats TB in Africa is now House's patient. In Diagnostics, he is being examined by House and his team, Allison Cameron, Robert Chase and Eric Foreman. House suggests that Sebastian leave.]

1. House: (...) Why don't you go wrack yourself with guilt in your own room?

2. Sebastian: No, thanks, I'll stay. I'd like to hear the differential.

3. House: Dr. Cameron, tell the doctor why it's not a good idea for the patient to be here.

4. Cameron: He's an immunologist and a TB expert.

5. House: That'll be very useful if we need somebody to say the words, "I think it's TB." [He looks around sniffs.] What is that?

6. Sebastian: Oh that. I'm sorry, that's my body powder. It's the only thing I've found that works in the Sahara. I, I'm kind of used to it, I don't even notice it.

7. House: Who thinks it smells like an elephant dung smoothie?

8. Cameron: It smells okay to me. [Sebastian laughs]

9. House: That is exactly why the patient shouldn't be in the room. If you can't tell a man that his cologne makes you want to puke, how are you going to tell him that he's an idiot?

10. Cameron: He's not an idiot.

11. House: Sure, you say that now, while he's in the room.

12. Sebastian: Look, I don't have time for this. It's TB.

13. House: Nope. The symptoms are too varied.

14. Sebastian: Well, if you haven't seen 10,000 cases I'd agree that's what you'd think.

15. House: Told you he's an idiot. You said you wanted a second opinion.

16. Sebastian: No, actually. My backers wanted a second opinion.

Episode 4, Season 2, "TB or Not TB"

In his first utterance in the interaction quoted above, House poses a question (1), which invites an answer on the addressee's part. The latter thus duly responds (2), directing his utterance to House, the addressee, and the collective third party, i.e. all the other doctors present. This prompts House to explicitly address Cameron (3) and mention one of the individuals constituting the collective third party (Sebastian) in the third person. House refers to Sebastian as if the latter were a nonparticipant who could not hear him, while actually meaning him to listen to the turn. A very similar strategy (talking about the third party in the third person) is deployed by Cameron (4), as well as in the other turns produced by Cameron (10) 
and House (11 and 15). While Cameron overtly observes Sebastian's hearership, House does not, even if tacitly ratifying him. In House's turns addressed to Cameron, Sebastian (the third party distinct from the collective third party comprised of the rest of the team) is treated with exacerbated impoliteness as if he were not a hearer who may take offence. Additionally, the same interactional phenomenon occurs, albeit indirectly, in House's two verbal contributions (5 and 9), which are based on generalisations yet imply that the unaddressed ratified hearer subscribes to the characteristics talked about. With its first part addressed to Cameron but also directed to two types of third parties (Sebastian, and the rest of the medical team) House's turn (5) closes with a question which seems to be addressed to all the hearers, inclusive of the hitherto marginalised third party, given the absence of non-verbal cues indicating otherwise. As envisaged by House, one of the addressees, who knows the answer, becomes the next speaker (6). Consequently, House asks another question (7) overtly based on the equipotentiality principle, and it is Cameron that takes the floor (8). As Sebastian's turn (12) indicates, the speaker may legitimately self-select entirely uninvited to do thus by other interlocutors, thereby instigating a new exchange within the same interaction (13-16). Interestingly, one of House's turns (15) changes its addressees halfway through. House first talks mainly to his team and then returns to the author of the preceding turn and following one (14 and 16).

\subsection{Ratifying an alleged overhearer as the third party}

It is here argued that a special type of the third party concerns any individual who might be considered an overhearer, given his/her social and/or spatial position, but is ratified by the speaker (and possibly also other ratified hearers), whether or not explicitly. This bold postulate put forward here is at odds with folk theory and other authors' claims. Importantly, it is Goffman that suggests that an overhearer may be "encouraged" (1981a [1976]: 9) or "intended" (1981c [1979]: 136). It may then be inferred that an individual remains an overhearer even if the speaker should purposefully direct his/her words to him/her. This premise, betraying Goffman's faithfulness to folk social notions, reverberates also in other authors' works (Levinson 1988; Clark and Schaefer 1992; Bell 1984, 1991). For instance, Levinson (1988) distinguishes the targeted overhear$e r$, who is a channel-linked recipient but is not overtly addressed and remains a non-participant. By the same token, Clark and Schaefer's (1992) contention is that overhearers can have meanings communicated to them. Accordingly, Clark and Schaefer (1992) champion a number of attitudes speakers may have towards overhearers: indifference (whereby speakers pay no heed to whether overhearers can grasp any meanings), concealment (via which speakers overtly hinder overhearers' understanding, which the latter acknowledge), disclosure (through which speakers design utterances with a view to being understood by overhearers), and disguisement (i.e. disclosure of a misrepresentation, thanks to which speakers "conspiratorily" facilitate overhearers' comprehension, inviting 
their ill-advised inferences). Admittedly, the first attitude is the one applicable to the overhearer and the second one may be as well, unless the communication channel is blocked and the overhearer becomes a non-participant. However, disclosure and disguisement are indicative of the speaker's ratification of a hearer, who thus ceases to be unratified.

Admittedly, the view that the concept of the overhearer encompasses also a listener who is actually invited to make inferences must be grounded in folk understanding of social situations. In non-theoretic terms, a physical context (e.g. being in a different room) or a social relation (e.g. being a stranger in a train compartment) will, by default, grant an individual an unratified status in an interaction held by other conversationalists (or in self-talk). This will have affected the scholarship and the widespread use of the notion "overhearer". In opposition to this prevalent opinion, it may be argued that if speakers intend to communicate meanings to overhearers (by deploying disclosure or disguisement), they must simultaneously ratify the latter. Accordingly, a statement is ventured that an ostensibly overhearing individual is actually a ratified hearer, notwithstanding his/her status determined by spatial positioning, law, or etiquette. This happens once the speaker directs, whether or not overtly, his/her utterance to such an individual, who thus assumes the position of a ratified hearer (Dynel 2010b). This thesis is premised on the assumption that the speaker normally does not intend overhearers to understand his/her utterances (Clark and Carlson 1982). Moreover, the speaker will frequently take precautionary measures not to be understood by an unratified participant, deploying a private key, for instance by speaking quietly, using argot or a foreign language, or capitalising on common-ground markers shared with ratified hearers (cf. Clark and Schaefer 1987). In essence, the speaker's intention to communicate meanings (whether truth-based or deceitful) to, and be understood accordingly by, a chosen hearer is here propounded as the primary criterion for the differentiation between ratified and unratified hearers (cf. Clark and Carlson 1982; Schober and Clark 1989; Clark and Schaefer 1992).

(7) [House calls Doctor Wilson, his friend, who is sitting at the charity poker table. House wants to ascertain that Doctor Lisa Cuddy, Dean of Medicine, is still playing and will not appear to supervise his patient.]

1. House: [He puts his phone onto speakerphone.] Keep your answers short and discreet. Is Cuddy still playing?

2. Wilson: The chicken is still in Piccadilly Square.

3. House: Brilliant. She'll never suspect that Normandy is her target.

4. Cuddy: Is that House? Tell him that the blinds just went to 2040 and he's running out of chips.

5. House: How's she doing?

6. Wilson: Well what's going on? The way you took off, something's obviously...

7. House: Love to chat but got a game to play. How's she doing? 
8. Wilson: The patient is on life support, we're about to pull the plug.

9. Cuddy: Are you talking about me?

10. House: And what have you got?

11. Wilson: Hmm... does sound like high dose cardio meds.

12. House: Two hearts. You got the flush?

13. Wilson: Still waiting on the final labs.

14. House: She drinking her seltzer?

15. Wilson: No, hydration is not a problem.

16. House: Means she's bluffing. Push her all in. [Wilson does so]

17. Cuddy: Call. [She flips her cards.] Two pair. Show me your hearts.

18. Wilson: [He flips his cards but only ends up having one pair] Seven of clubs. [Cuddy cackles]

19. House: Oh dear, sounds like I messed up. You're going to be stuck with her for a while. Talk to you soon. [He puts down the phone]

20. Cuddy: Ohoho! Yes!

Episode 17, Season 2, "All in"

Conversing with House on the mobile phone, Wilson tries to hide the meanings he wishes to communicate to him from Cuddy, who cannot be considered a bystander to his utterances, for she is invited to make inferences, albeit ill-advised. Specifically, taking cognisance of the fact that Cuddy can hear and, in all likelihood, will listen, Wilson disguises his turns $(2,8,11,13$, and 15) so that she cannot appreciate the meanings he genuinely conveys to the addressee at the other end of the line. Wilson thus deliberately deploys the strategy of disguisement with a view to misleading Cuddy. She must be conceptualised as the third party when listening to the turns, inasmuch as the speaker she can hear does mean to convey meanings to her. House, on the other hand, grasps the import of Wilson's utterances on the understanding that they are veiled as medical talk for the sake of Cuddy's misguided understanding, whilst he does not need to employ this deceptive strategy, his only hearer being Wilson. Interestingly, in the light of the utterance whose inept disguisement is abundantly clear (2), Cuddy manages to infer that Wilson's interlocutor is House, which shows in the utterance she addresses to the former (4). This is why Wilson has no reservations about revealing, albeit implicitly, that it is House that he is talking with (6). However, as House deflects and asks about the situation in the casino (7), Wilson decides to resort to disguisement in order to promote Cuddy's faulty understanding. Even though Wilson uses a metaphor of a hospitalised patient (8), Cuddy again rightly suspects that she is the one talked about (9), yet she does not probe the issue further, irrespective of being able to hear and, most likely, listening to Wilson's turns addressed to House $(11,13,15)$. It is also difficult to judge if Cuddy is well aware that Wilson takes into account her listening and thus modifies his turns to deceive her.

Interestingly, the ratification of an individual may be also dependent on the speaker's pretended obliviousness to an overhearer, whilst employing disguisement so that the latter should consider himself/herself an eavesdropper. 
(8) [House and his best friend, Dr Wilson, are exiting an elevator and discussing a case. Earlier in the episode, House's underage patient escaped to the roof, which is why House was summoned at night. He met Dr Cuddy at the hospital entrance. In reply to her naive question as to whether he was seeing a patient, House said that he was meeting a prostitute (referring to her as "a hooker").]

1. Wilson: You actually treated him?

2. House: All I know is that he sued some doctors, who am I to assume that they didn't have it coming to them. [He stops when he sees Cuddy coming and speaks much louder] The cutest little tennis outfit, my God I thought I was going to have a heart attack. [He acts as if he had just realized that Cuddy was there] Oh my, I didn't see you there, that is so embarrassing.

3. Cuddy: How's your hooker doing?

4. House: Oh, sweet of you to ask, funny story, she was going to be a hospital administrator but hated having to screw people like that.

Episode 2, Season 1, "Paternity"

House's dyadic conversation with Wilson terminates halfway through the former's turn (2), as soon as he realises that Cuddy is in vicinity, at which point he ratifies her as the third party, even if he pretends to be oblivious to her. If the speaker were indeed heedless of the hearer, the latter would assume the position of an eavesdropper. That House ratifies Cuddy in his turn addressed to Wilson manifests itself in the sudden change of the topic from the professional one to a taboo one and the fact that he speaks much louder so that she can hear. It is only in the final part of his turn (2) that House explicitly appreciates Cuddy's presence and addresses her, changing Wilson's role to that of the third party. It is difficult to tell whether or not Cuddy appreciates House's failed attempt at deception and her covert ratified status (rather than the status of an eavesdropper) at the first stage of House's turn that she can hear. Once openly acknowledged as the hearer, she retorts (3), and thereby she contributes to the interaction, linking the import of House's verbalisation to an earlier event. She teases House, who responds accordingly and playfully (thanks to the lexical ambiguity) puts her down (4). Finally, it should be noted that Wilson's role in these two turns produced by House and Cuddy is that of a third party, specifically the spectator.

\section{Conclusions}

This paper elaborated on a number of issues related to ratified participation at the reception end. In conformity with the prevailing view that dichotomises ratified hearers into two types, two labels were proposed here: the addressee and the third party. A number of issues were addressed and elucidated as regards the definition of and differentiation between the two hearer categories. It was proposed that 
the addressee can be told from the third party thanks to the turn's relevance to a hearer (including interactional coherence), as well as (non-)verbal cues, even though the latter may be elusive or insufficient.

Most importantly, several subtypes of the third parties were listed: the third party enjoying rights equal to the addressee's, the third party as the primary listener with the use of the dummy addressee, the third party as a spectator or referee/judge, and the seemingly neglected third party. These roles, with the list being potentially subject to expansion, have not been discussed in the literature hitherto.

Finally, a postulate was propounded here that if the speaker intentionally directs an utterance to an individual commonly perceived as an overhearer, given their spatial positioning and/or societal norms, the latter should actually be conceptualised as a special type of the third party, whether or not he/she acknowledges his/her ratified status.

\section{Notes}

1 What Goffman means by "recipient" is here captured under the terms "hearer" and "listener".

2 In contrast to the indirect target, the audience is not the recipient, i.e. "someone who a message is for; it is thus perhaps essentially a role defined by the pertinence of the informational (or attitudinal) content" (Levinson 1988: 178). Here, the notion of a neglected third party serves as a substitute for the "audience", a label which brings to mind the recipients of media talk.

3 It should also be mentioned that gaze is not always available to the viewer, given that camera angles may fail to bring out at whom exactly the speaker is looking or where each of the hearers is standing.

\section{References}

Bell, Allan (1984) "Language style as audience design." Language and Society 13, 145-204.

Bell, Allan (1991) The Language of News Media. Oxford: Blackwell.

Clark, Herbert (1996) Using Language. Cambridge: Cambridge University Press.

Clark, Herbert and Thomas Carlson (1982) "Hearers and speech acts." Language 58, 332-372.

Clark, Herbert and Edward Schaefer (1987) "Concealing one's meaning from overhearers." Journal of Memory and Language 26, 209-225.

Clark, Herbert and Edward Schaefer (1992) "Dealing with overhearers." In: Clark, Herbert (ed.) Arenas of Language Use. Chicago: University of Chicago Press, 248-273.

Coupland, Nikolas (2004) "Stylised deception." In: Jaworski, Adam, Nikolas Coupland and Dariusz Galasiński (eds.) Metalanguage: Social and Ideological Perspectives. Berlin, New York: Mouton de Gruyter, 249-274.

Dynel, Marta (2010a) "Friend or foe? Chandler's humour from the metarecipient's perspective." In: Witczak-Plisiecka, Iwona (ed.), Pragmatic Perspectives on Language and Linguistics Vol. II: Pragmatics of Semantically Restricted Domains. Newcastle: Cambridge Scholars Publishing, 175-205.

Dynel, Marta (2010b) "Not hearing things - Hearer/listener categories in polylogues." mediAzioni 9. http://mediazioni.sitlec.unibo.it, ISSN 1974-4382 
Dynel, Marta (2010c) “On 'Revolutionary Road': A proposal for extending the Gricean model of communication to cover multiple hearers." Lodz Papers in Pragmatics 6.2, 283-304.

Dynel, Marta (2011a) “'You talking to me?' The viewer as a ratified hearer." Journal of Pragmatics $43,1628-1644$.

Dynel, Marta (2011b) "Stranger than fiction? A few methodological notes on linguistic research in film discourse." Brno Studies in English 37 (1), 41-61.

Dynel, Marta (2011c) "Revisiting Goffman's postulates on participant statuses in verbal interaction." Language and Linguistics Compass. Sociolinguistics 5 (7), 454-465.

Dynel, Marta (2012) "Setting our House in order: The workings of impoliteness in multi-party film discourse." Journal of Politeness Research 8: 161-194.

Goffman, Erving (1981a) "Replies and responses.” In: Forms of Talk. Philadelphia: University of Pennsylvania Press, 5-77. [Originally published as Goffman, Erving (1976) "Replies and responses." Language in Society 5, 257-313.]

Goffman, Erving (1981b) "Response cries." In: Forms of Talk. Philadelphia: University of Pennsylvania Press, 78-123. [Originally published as Goffman, Erving (1978) "Response cries." Language 54, 787-815.]

Goffman, Erving (1981c) "Footing." In: Forms of Talk. Philadelphia: University of Pennsylvania Press, 124-159. [Originally published as Goffman, Erving (1979) "Footing." Semiotica 25, 1-29.]

Goffman, Erving (1981d) "Radio talk: A study of the ways of our errors." Forms of Talk. Philadelphia: University of Pennsylvania Press, 197-330.

Goodwin, Charles (1979) "The interactive construction of a sentence in natural conversation." In: George Psathas (ed.) Everyday Language: Studies in Ethnomethodology. New York: Irvington, 97-121.

Goodwin, Charles (1981) Conversational Organization: Interaction Between Speakers and Hearers. New York: Academic Press.

Grimshaw, Allen (ed.). 1996 [1990]. Conflict Talk: Sociolinguistic Investigations in Conversations. Cambridge: Cambridge University Press.

Hymes, Dell (1972) "Models of the interaction of language and social life." In: John Gumperz and Dell Hymes (eds.) Directions in Sociolinguistics: The Ethnography of Communication. New York: Holt, Rinehart and Winston, 35-71.

Hymes, Dell (1974) Foundations in Sociolinguistics: An Ethnographic Approach. University of Pennsylvania Press.

Levinson, Stephen (1988) "Putting linguistics on a proper footing: Explorations in Goffman's participation framework." In: Paul Drew and Anthony Wootton (eds.) Erving Goffman: Exploring the Interaction Order. Oxford: Polity Press, 161-227.

Sacks, Harvey, Emanuel Schegloff and Gail Jefferson (1974) "A simplest systematics for the organisation of turn-taking for conversation." Language 50, 696-735.

Schegloff, Emanuel and Harvey Sacks (1973) "Opening up closings." Semiotica 8, 289-327.

Schober, Michael and Herbert Clark (1989) "Understanding by addressees and overhearers." Cognitive Psychology 21, 211-232.

Sidnell, Jack (2009) "Participation.” In: Sigurd D'hondt, Jan-Ola Östman and Jef Verschueren (eds.) The Pragmatics of Interaction. Amsterdam: John Benjamins, 125-156.

Thomas, Jenny (1986) The dynamics of discourse: A pragmatic analysis of confrontational interaction. Unpublished $\mathrm{PhD}$ thesis, Lancaster University, UK.

Verschueren, Jef (1999) Understanding Pragmatics. London: Arnold. 
Marta Dynel is professor in the Department of Pragmatics in the Institute of English at the University of Łódź. She has published internationally in linguistic journals and volumes. Her research interests are primarily in pragmatic, cognitive and sociolinguistic mechanisms of humour, neoGricean studies, (im)politeness, as well as in the methodology of film discourse analysis, and the pragmatics of interaction.

Address: Dr Marta Dynel, University of Łódź, Department of Pragmatics, Institute of English, ul. Pomorska 171/173, 90-263 Łódź, Poland. [email: marta.dynel@yahoo.com] 